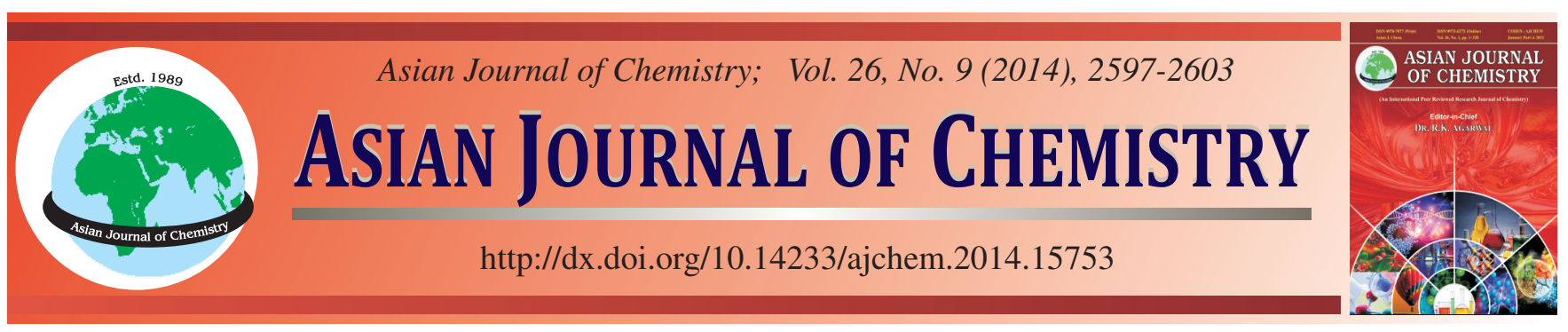

\title{
Oxidation of Organic Sulfides by Imidazolium Fluorochromate: A Kinetic and Mechanistic Approach
}

\author{
Lokesh Mathur, A. Choudhary, Om Prakash and Pradeep K. Sharma*
}

Department of Chemistry, J.N.V. University, Jodhpur-342 005, India

*Corresponding author: E-mail: drpkvs27@yahoo.com

\begin{abstract}
The oxidation of organic sulfides by imidazolium fluorochromate resulted in the formation of the corresponding sulfoxides. The reaction is first order with respect to imidazolium fluorochromate. A Michaelis-Menten type kinetics was observed with respect to the reactants. The reaction is catalyzed by toluene- $p$-sulfonic acid. The oxidation was studied in nineteen different organic solvents. An analysis of the solvent effect by Swain's equation showed that the both cation- and anion-solvating powers of the solvents play important roles. The correlation analyses of the rate of oxidation of thirty four sulfides were performed in terms of various single and multiparametric equations. For the aryl methyl sulfides, the best correlation is obtained with Charton's LDR and LDRS equations. The oxidation of alkyl phenyl sulfides exhibited a good correlation in terms of Pavelich-Taft equation. The polar reaction constants are negative indicating an electrondeficient sulfur centre in the rate-determining step. A mechanism involving formation of a sulphenium cation intermediate in the slow step has been proposed.
\end{abstract}

Keywords: Correlation analysis, Halochromate, Kinetics, Mechanism, Oxidation.

\section{INTRODUCTION}

Various halochromates have been used as mild and selective oxidizing reagents in synthetic organic chemistry ${ }^{1}$. Imidazolium fluorochromate (IFC) is also one of such compounds used for the oxidation of benzylic alcohols ${ }^{2}$. We have been interested in the kinetic and mechanistic aspects of the oxidation by complexed $\mathrm{Cr}(\mathrm{VI})$ species and several reports on halochromates have already reported from our laboratory ${ }^{3-6}$. It is, known that mode of oxidation depends upon the nature of counter-ion attached to the chromium anion. Karunakaran et. $a l{ }^{7}$ have reported a common mechanism for the oxidation of diphenyl sulfide by various $\mathrm{Cr}(\mathrm{VI})$ reagents in acetic acid. In the present article, we report the kinetics of oxidation of thirty-four organic sulfides by IFC in dimethyformamide as solvent. Attempts have been made to correlate rate and structure in this reaction. A probable mechanism has been proposed.

\section{EXPERIMENTAL}

The sulfides were either commercial products or prepared by known methods ${ }^{8}$ and were purified by distillation under reduced pressure or crystallization. Their purity was checked by comparing their boiling or melting points with the literature values. Imidazolium fluorochromate was prepared by the reported method ${ }^{2}$. Toluene- $p$-sulfonic acid $(\mathrm{TsOH})$ was used as a source of hydrogen ions.
Product analysis: $\mathrm{MeSPh}$ or $\mathrm{Me}_{2} \mathrm{~S}(0.1 \mathrm{~mol})$ and IFC $(0.01 \mathrm{~mol})$ was dissolved in DMSO $(50 \mathrm{~mL})$ and the mixture was allowed to stand for $20 \mathrm{~h}$. Most of the solvent was removed under reduced pressure. The residue was diluted with water and extracted with chloroform $(3 \times 50 \mathrm{~mL})$. The chloroform layer was dried over anhydrous magnesium sulfate, the solvent was removed by evaporation and the residue was analysed by IR and ${ }^{1} \mathrm{H}$ NMR spectroscopy. The spectra were identical with those of the corrsponding sulfoxides. Peaks characteristic of the sulfide and sulfone could not be detected. In IR spectra, the product showed a strong and broad absorption at 1050 $\mathrm{cm}^{-1}$. No band either at 1330 or $1135 \mathrm{~cm}^{-1}$, characteristic of sulfones $^{9}$ was seen. In NMR spectroscopy, studied in the case of $\mathrm{Me}_{2} \mathrm{~S}$, the peak due to methyl protons shifted from $2.1 \mathrm{ppm}$, in the sulfide, to $2.6 \mathrm{ppm}$ in the product. In the corresponding sulfone, the peak should have appeared at $3.0 \mathrm{ppm}^{10}$. Similar experiments were performed with the other sulfides also. In all cases, the products were the corresponding sulfoxides. The oxidation state of chromium in completely reduced reaction mixtures, determined by an iodometric method, was $3.90 \pm$ 0.15 .

Kinetic measurements: The reactions were studied under pseudo-first-order conditions by keeping an excess $(\times 15$ or greater) of the sulfide over IFC. The solvent was DMSO, unless mentioned otherwise. The reactions were studied at constant 
temperature $( \pm 0.1 \mathrm{~K})$ and were followed by monitoring the decrease in the concentration of IFC at $370 \mathrm{~nm}$ for up to $80 \%$ reaction extent. Pseudo-first-order rate constants, $\mathrm{k}_{\mathrm{obs}}$, were evaluated from linear plots $\left(r^{2}>0.995\right)$ of $\log$ [IFC] against time. Duplicate kinetic runs showed that the rate constants are reproducible to within $\pm 3 \%$. All kinetic runs, except those for studying the effect of acidity, were studied in the absence of $\mathrm{TsOH}$. The values of the second order rate constants were computed from the relation $\mathrm{k}_{2}=\mathrm{k}_{\mathrm{obs}} /$ [sulfide]. Simple and multivariate regression analyses were carried out by the leastsquares method.

\section{RESULTS AND DISCUSSION}

The oxidation of organic sulfides by IFC resulted in the formation of the corresponding sulfoxides. The overall reaction may be represented as eqn (1).

$\mathrm{R}-\mathrm{S}-\mathrm{R}^{\prime}+\mathrm{O}_{2} \mathrm{CrClOImH}$<smiles>[R]S(=[R])(=O)OC(=O)O</smiles>

Rate law: The reactions are of first order with respect to IFC. Fig. 1 depicts a typical kinetic run. Further, the pseudofirst order rate constant, $\mathrm{k}_{\mathrm{obs}}$ is independent of the initial concentration of IFC. The reaction rate increases with increase in the concentration of the sulfide but not linearly (Table-1). A plot of $1 / \mathrm{k}_{\text {obs }}$ against $1 /[$ Sulfide] is linear $(r>0.995)$ with an intercept on the rate-ordinate (Fig. 2). Thus, Michaelis-Menten type kinetics are observed with respect to the sulfide. This leads to the postulation of following overall mechanism (2) and (3) and rate law (4).

$$
\begin{aligned}
& \text { Sulfide + IFC } \stackrel{\mathbf{K}}{\underset{\mathbf{k}_{2}}{\rightleftharpoons}} \text { [complex] } \\
& \text { [Complex }] \longrightarrow \text { Products }
\end{aligned}
$$

$$
\text { Rate } \left.\left.\left.=\mathrm{k}_{2} \mathrm{~K} \text { [Sulfide }\right] \text { [IFC]/(1+K [Sulfide }\right]\right)
$$

The dependence of reaction rate on the reductant concentration was studied at different temperatures and the values of $\mathrm{K}$ and $\mathrm{k}_{2}$ were evaluated from the double reciprocal plots. The thermodynamic parameters of the complex formation and activation parameters of the decomposition of the complexes were calculated from the values of $\mathrm{K}$ and $\mathrm{k}_{2}$ respectively at different temperatures (Tables 3 and 4). Fig. 2 depict a typical kinetic run.

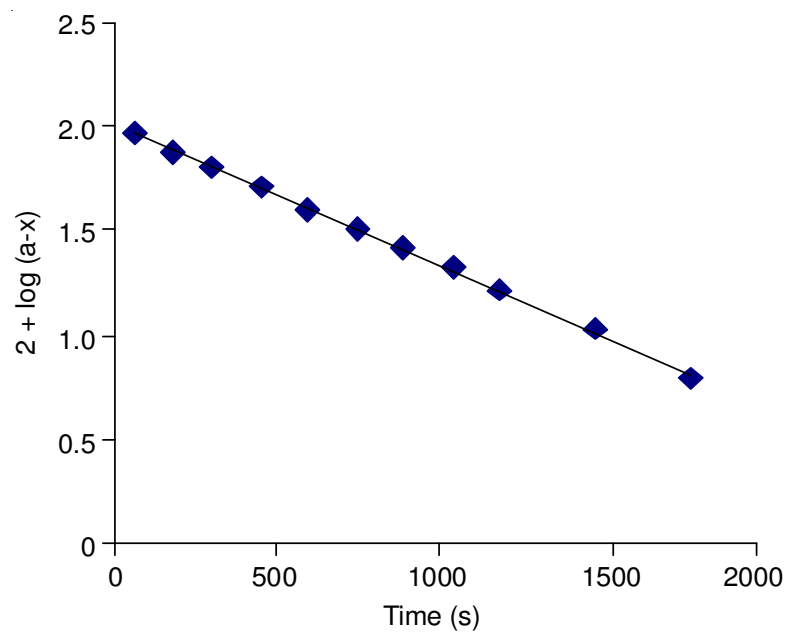

Fig. 1. Oxidation of methyl phenyl sulphite by IFC: A typical kinetic run

\begin{tabular}{|c|c|c|c|}
\hline \multicolumn{4}{|c|}{$\begin{array}{l}\text { TABLE-1 } \\
\text { RATE CONSTANTS FOR THE OXIDATION OF } \\
\text { METHYL PHENYL SULFIDE BY IFC AT } 298 \mathrm{~K}\end{array}$} \\
\hline 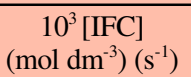 & $\begin{array}{c}\mathrm{MeSPh}] \\
\left(\mathrm{mol} \mathrm{dm}^{-3}\right)\end{array}$ & $\begin{array}{c}{[\mathrm{TsOH}]} \\
\left(\mathrm{mol} \mathrm{dm}^{-3}\right)\end{array}$ & $\begin{array}{c}10^{4} \mathrm{k}_{\mathrm{ob}} \\
\left(\mathrm{s}^{-1}\right)\end{array}$ \\
\hline 1.0 & 0.10 & 0.0 & 5.49 \\
\hline 1.0 & 0.20 & 0.0 & 8.02 \\
\hline 1.0 & 0.40 & 0.0 & 10.5 \\
\hline 1.0 & 0.60 & 0.0 & 11.7 \\
\hline 1.0 & 0.80 & 0.0 & 12.5 \\
\hline 1.0 & 1.00 & 0.0 & 12.9 \\
\hline 1.0 & 1.50 & 0.0 & 13.6 \\
\hline 1.0 & 3.00 & 0.0 & 14.4 \\
\hline 2.0 & 0.20 & 0.0 & 8.19 \\
\hline 4.0 & 0.20 & 0.0 & 7.83 \\
\hline 6.0 & 0.20 & 0.0 & 8.01 \\
\hline 8.0 & 0.20 & 0.0 & 7.92 \\
\hline 1.0 & $0.40^{*}$ & 0.0 & $12.6^{*}$ \\
\hline
\end{tabular}

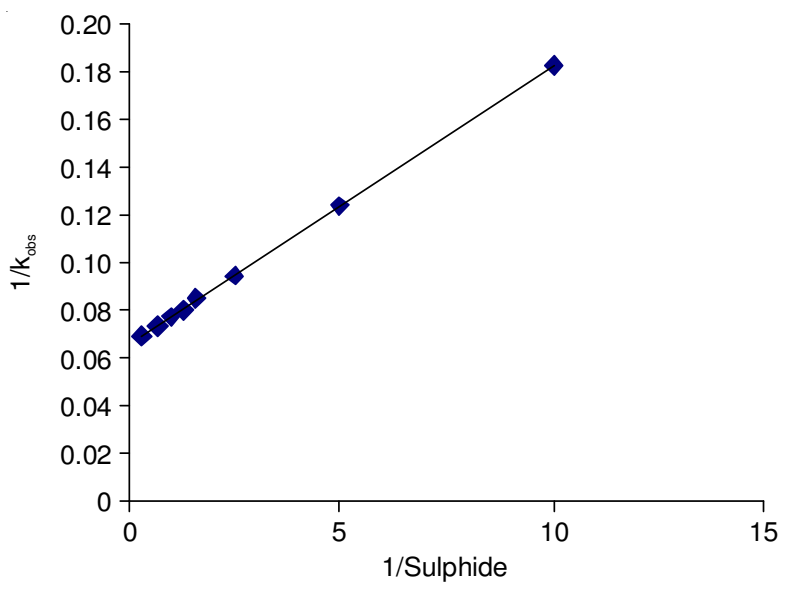

Fig. 2. $1 / \mathrm{k}_{\mathrm{obs}}$ vs. 1/[Sulfide]: A double reciprocal plot

Test for free radicals: The oxidation of methyl phenyl sulfide, in an atmosphere of nitrogen, failed to induce the polymerization of acrylonitrile. Further, the addition of acrylonitrile had no effect on the rate of oxidation (Table-1). To further confirm the absence of free radicals in the reaction pathway, the reaction was carried out in the presence of $0.05 \mathrm{~mol} \mathrm{dm}^{-3}$ of 2,6-di-t-butyl-4-methylphenol (butylated hydroxytoluene or BHT). It was observed that BHT was recovered unchanged, almost quantitatively.

Effect of substituents: The rates of oxidation of a number of ortho-, meta- and para-substituted phenyl methyl sulfides, alkyl phenyl sulfides, dialkyl sulfides and diphenyl sulfide were determined at different temperatures and the activation parameters were calculated (Table-3).

Effect of acidity: The reaction is catalyzed by TsOH (Table2). The $\mathrm{TsOH}$-dependence has the form $\mathrm{k}_{\mathrm{obs}}=\mathrm{a}+\mathrm{b}[\mathrm{TsOH}]$. The values of $\mathrm{a}$ and $\mathrm{b}$ for methyl phenyl sulfide are $5.21 \pm 0.12 \pm 10^{-4}$ $\mathrm{s}^{-1}$ and $9.25 \pm 0.20 \pm 10^{-4} \mathrm{~mol}^{-1} \mathrm{dm}^{3} \mathrm{~s}^{-1}$ respectively $\left(\mathrm{r}^{2}=0.9980\right)$. Therefore, the experimental rate law has the following form:

Rate $=\mathrm{k}_{2}[$ IFC $]$ [sulfide $]+\mathrm{k}_{3}$ [IFC] [sulfide $][\mathrm{TsOH}](5)$

Effect of solvent: The oxidation of methyl phenyl sulfide was studied in nineteen different organic solvents. The choice of solvent was limited by the solubility of IFC and its reaction with primary and secondary alcohols. There was no reaction 


\begin{tabular}{|c|c|c|c|c|c|c|c|}
\hline \multicolumn{8}{|c|}{$\begin{array}{c}\text { TABLE-2 } \\
\text { DEPENDENCE OF THE REACTION RATE ON HYDROGEN-ION CONCENTRATION }\end{array}$} \\
\hline \multicolumn{2}{|c|}{ [Sulphide] $0.10\left(\mathrm{~mol} \mathrm{dm}^{-3}\right)$} & \multicolumn{4}{|c|}{ [IFC] $0.001\left(\mathrm{~mol} \mathrm{dm}^{-3}\right)$} & \multicolumn{2}{|c|}{ Temprature $298 \mathrm{~K}$} \\
\hline \multirow{2}{*}{\multicolumn{2}{|c|}{$\begin{array}{c}{[\mathrm{TsOH}]\left(\mathrm{mol} \mathrm{dm}^{-3}\right)} \\
10^{4} \mathrm{k}_{\mathrm{obs}}\left(\mathrm{s}^{-1}\right) \\
\end{array}$}} & 0.10 & 0.20 & 0.40 & 0.60 & 0.80 & 1.00 \\
\hline & & 6.15 & 7.18 & 8.91 & 10.5 & 12.6 & 14.6 \\
\hline \multicolumn{8}{|c|}{$\begin{array}{c}\text { TABLE }-3 \\
\text { RATE CONSTANTS FOR THE DECOMPOSITION OF IFC-SULFIDES COMPLEXES AND ACTIVATION PARAMETERS }\end{array}$} \\
\hline \multirow{2}{*}{ Subst. } & \multicolumn{4}{|c|}{$10^{4} \mathrm{k}_{2}\left(\mathrm{dm}^{3} \mathrm{~mol}^{-1} \mathrm{~s}^{-1}\right)$} & \multirow{2}{*}{$\begin{array}{c}\Delta \mathrm{H}^{*} \\
\left(\mathrm{~kJ} \mathrm{~mol}^{-1}\right)\end{array}$} & \multirow{2}{*}{$\begin{array}{c}-\Delta \mathrm{S}^{*} \\
\left(\mathrm{~mol}^{-1} \mathrm{~K}^{-1}\right)\end{array}$} & \multirow{2}{*}{$\begin{array}{c}\Delta \mathrm{G}^{*} \\
\left(\mathrm{~kJ} \mathrm{~mol}{ }^{-1}\right)\end{array}$} \\
\hline & $288 \mathrm{~K}$ & $298 \mathrm{~K}$ & $308 \mathrm{~K}$ & $318 \mathrm{~K}$ & & & \\
\hline $\mathrm{H}$ & 5.49 & 15.2 & 40.6 & 98.1 & $70.3 \pm 0.2$ & $62 \pm 1$ & $89.1 \pm 0.2$ \\
\hline$p$-Me & 11.3 & 30.1 & 77.4 & 180 & $67.9 \pm 0.3$ & $66 \pm 1$ & $87.4 \pm 0.2$ \\
\hline$p$-OMe & 24.9 & 64.6 & 162 & 360 & $65.5 \pm 0.4$ & $68 \pm 1$ & $85.5 \pm 0.3$ \\
\hline$p-\mathrm{F}$ & 5.81 & 16.2 & 45.0 & 108 & $72.0 \pm 0.5$ & $57 \pm 2$ & $88.9 \pm 0.3$ \\
\hline$p-\mathrm{Cl}$ & 3.84 & 11.0 & 30.6 & 76.6 & $73.6 \pm 0.3$ & $55 \pm 1$ & $89.9 \pm 0.3$ \\
\hline$p-\mathrm{NO}_{2}$ & 0.37 & 1.20 & 3.78 & 10.7 & $83.0 \pm 0.4$ & $42 \pm 1$ & $95.3 \pm 0.3$ \\
\hline$p$-COMe & 0.88 & 2.70 & 8.01 & 21.4 & $78.8 \pm 0.2$ & $50 \pm 1$ & $93.3 \pm 0.2$ \\
\hline$p$-COOMe & 1.26 & 3.78 & 11.0 & 28.8 & $77.1 \pm 0.3$ & $52 \pm 1$ & $92.5 \pm 0.2$ \\
\hline$p-\mathrm{Br}$ & 3.77 & 10.8 & 30.1 & 75.5 & $73.7 \pm 0.4$ & $55 \pm 1$ & $89.9 \pm 0.3$ \\
\hline$p$-NHAc & 12.6 & 33.8 & 87.3 & 204 & $68.3 \pm 0.3$ & $64 \pm 1$ & $87.1 \pm 0.2$ \\
\hline$p-\mathrm{NH}_{2}$ & 82.8 & 198 & 468 & 990 & $60.7 \pm 0.4$ & $74 \pm 1$ & $82.7 \pm 0.3$ \\
\hline$m$-Me & 9.88 & 26.1 & 67.5 & 153 & $67.3 \pm 0.5$ & $69 \pm 2$ & $87.7 \pm 0.4$ \\
\hline$m$-OMe & 11.7 & 30.6 & 75.6 & 171 & $65.5 \pm 0.2$ & $73 \pm 1$ & $87.4 \pm 0.2$ \\
\hline$m-\mathrm{Cl}$ & 2.04 & 5.88 & 16.3 & 40.8 & $73.7 \pm 0.3$ & $60 \pm 1$ & $91.4 \pm 0.2$ \\
\hline$m$-Br & 2.01 & 5.79 & 16.1 & 40.3 & $73.8 \pm 0.2$ & $60 \pm 1$ & $91.5 \pm 0.2$ \\
\hline$m$-I & 2.37 & 6.75 & 18.6 & 46.3 & $73.1 \pm 0.3$ & $61 \pm 1$ & $91.1 \pm 0.2$ \\
\hline$m-\mathrm{NO}_{2}$ & 0.23 & 0.75 & 2.36 & 6.66 & $83.1 \pm 0.3$ & $46 \pm 1$ & $96.5 \pm 0.2$ \\
\hline$m-\mathrm{CO}_{2} \mathrm{Me}$ & 1.04 & 3.12 & 9.08 & 23.4 & $76.7 \pm 0.3$ & $55 \pm 1$ & $93.0 \pm 0.3$ \\
\hline$o$-Me & 2.33 & 6.93 & 19.8 & 51.3 & $76.1 \pm 0.2$ & $51 \pm 1$ & $91.0 \pm 0.2$ \\
\hline$o$-OMe & 6.39 & 18.0 & 48.1 & 117 & $71.4 \pm 0.1$ & $59 \pm 1$ & $88.7 \pm 0.1$ \\
\hline$o-\mathrm{NO}_{2}$ & 0.12 & 0.43 & 1.44 & 4.38 & $88.9 \pm 0.2$ & $31 \pm 1$ & $97.9 \pm 0.2$ \\
\hline$o$-COOMe & 0.29 & 0.95 & 30.6 & 8.91 & $84.6 \pm 0.4$ & $38 \pm 1$ & $95.9 \pm 0.3$ \\
\hline$o-\mathrm{Cl}$ & 0.63 & 20.2 & 6.26 & 17.1 & $81.5 \pm 0.4$ & $43 \pm 1$ & $94.1 \pm 0.3$ \\
\hline$o-\mathrm{Br}$ & 0.46 & 1.52 & 4.81 & 13.5 & $83.4 \pm 0.3$ & $39 \pm 1$ & $94.8 \pm 0.2$ \\
\hline$o-\mathrm{I}$ & 0.35 & 1.18 & 3.81 & 11.2 & $85.6 \pm 0.2$ & $34 \pm 1$ & $95.4 \pm 0.2$ \\
\hline$o-\mathrm{NH}_{2}$ & 20.7 & 54.0 & 135 & 306 & $66.0 \pm 0.3$ & $67 \pm 1$ & $86.0 \pm 0.3$ \\
\hline \multicolumn{8}{|c|}{ (ii) Alkyl phenyl sulfides } \\
\hline Et & 9.18 & 25.2 & 66.6 & 161 & $70.3 \pm 0.2$ & $59 \pm 1$ & $87.8 \pm 0.2$ \\
\hline $\operatorname{Pr}$ & 5.85 & 17.1 & 48.1 & 122 & $74.7 \pm 0.2$ & $48 \pm 1$ & $88.8 \pm 0.2$ \\
\hline$i-\operatorname{Pr}$ & 7.74 & 22.5 & 64.4 & 165 & $75.4 \pm 0.4$ & $43 \pm 1$ & $88.1 \pm 0.3$ \\
\hline$t$-Bu & 2.14 & 6.58 & 19.8 & 58.5 & $81.4 \pm 0.8$ & $33 \pm 3$ & $91.1 \pm 0.6$ \\
\hline \multicolumn{8}{|c|}{ (iii) Other sulfides } \\
\hline $\mathrm{Me}_{2} \mathrm{~S}$ & 11.7 & 28.8 & 73.8 & 180 & $67.0 \pm 0.9$ & $69 \pm 3$ & $87.4 \pm 0.8$ \\
\hline $\mathrm{Pr}_{2} \mathrm{~S}$ & 18.0 & 43.2 & 112 & 255 & $65.3 \pm 0.9$ & $71 \pm 3$ & $86.4 \pm 0.7$ \\
\hline $\mathrm{Ph}_{2} \mathrm{~S}$ & 2.16 & 6.12 & 18.0 & 48.6 & $76.8 \pm 0.9$ & $49 \pm 3$ & $91.2 \pm 0.7$ \\
\hline
\end{tabular}

with the solvent chosen. The kinetics were similar in all the solvents. The values of $\mathrm{k}_{2}$ and $\mathrm{K}$ are recorded in Table-5.

There is a linear correlation between the activation enthalpies and entropies of the oxidation of the thirty-four sulfides $(r=0.9432)$, indicating the operation of a compensation effect ${ }^{11}$. A correlation between the calculated values of enthalpies and entropies is often vitiated by the experimental errors associated with them. The reaction, however, exhibited an excellent isokinetic relationship, as determined by Exner's method ${ }^{12}$. An Exner's plot between $\log \mathrm{k}_{2}$ at $288 \mathrm{~K}$ and at $318 \mathrm{~K}$ was linear $\left(r^{2}=0.9964\right.$, slope $\left.=0.8302 \pm 0.0090\right)($ Fig. 3). The value of isokinetic temperature evaluated from the Exner's plot is 651 $\pm 43 \mathrm{~K}$. The linear isokinetic correlation implies that all the sulfides are oxidized by the same mechanism and the change in the rate of oxidation is governed by changes in both the enthalpy and entropy of the activation.

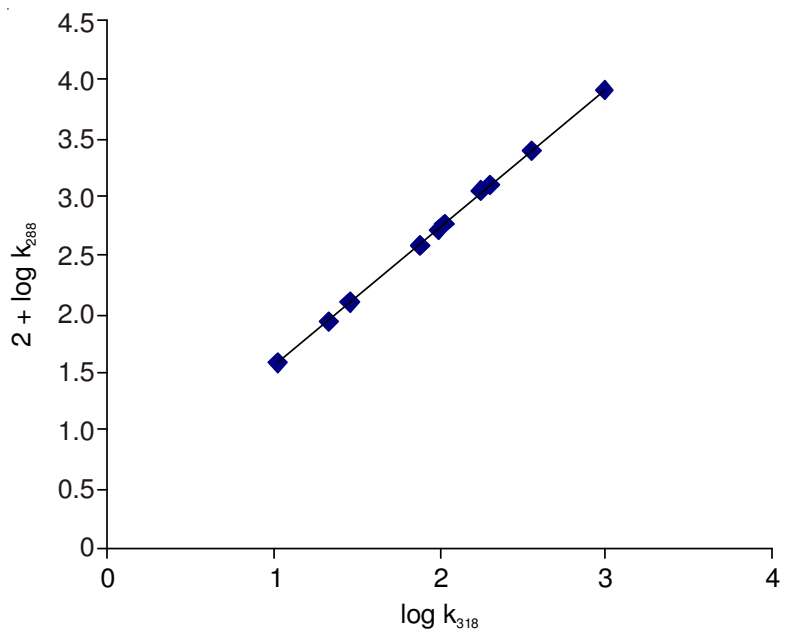

Fig. 3. Exner's isokinetic relationship in the oxidation of sulphides by IFC 
TABLE - 4

FORMATION CONSTANTS FOR THE DECOMPOSITION OF IFC-SULFIDE COMPLEXES AND THERMODYNAMIC PARAMETERS

\begin{tabular}{|c|c|c|c|c|c|c|c|}
\hline \multirow{2}{*}{ Diols } & \multicolumn{4}{|c|}{$\mathrm{K}\left(\mathrm{dm}^{3} \mathrm{~mol}^{-1}\right)$} & \multirow{2}{*}{$\begin{array}{c}-\Delta \mathrm{H}^{*} \\
\left(\mathrm{~kJ} \mathrm{~mol}^{-1}\right)\end{array}$} & \multirow{2}{*}{$\begin{array}{c}-\Delta S \\
\left(\mathrm{~mol}^{-1} \mathrm{~K}^{-1}\right)\end{array}$} & \multirow{2}{*}{$\begin{array}{c}-\Delta \mathrm{G}^{*} \\
\left(\mathrm{~kJ} \mathrm{~mol}^{-1}\right)\end{array}$} \\
\hline & 288 & 298 & 308 & $318 \mathrm{~K}$ & & & \\
\hline $\mathrm{H}$ & 6.15 & 5.66 & 4.80 & 4.05 & $13.2 \pm 0.9$ & $22 \pm 3$ & $6.70 \pm 0.7$ \\
\hline$p$-Me & 6.22 & 5.40 & 4.62 & 3.78 & $15.0 \pm 0.7$ & $29 \pm 2$ & $6.64 \pm 0.5$ \\
\hline$p$-OMe & 5.89 & 5.09 & 4.23 & 3.46 & $16.0 \pm 0.6$ & $33 \pm 2$ & $6.47 \pm 0.5$ \\
\hline$p-\mathrm{F}$ & 5.56 & 4.76 & 3.96 & 3.15 & $16.8 \pm 0.8$ & $36 \pm 3$ & $6.31 \pm 0.6$ \\
\hline$p-\mathrm{Cl}$ & 5.44 & 4.63 & 3.80 & 3.03 & $17.3 \pm 0.7$ & $38 \pm 2$ & $6.23 \pm 0.6$ \\
\hline$p-\mathrm{NO}_{2}$ & 5.81 & 5.02 & 4.20 & 3.39 & $16.1 \pm 0.7$ & $33 \pm 2$ & $6.44 \pm 0.6$ \\
\hline$p$-COOMe & 5.90 & 5.10 & 4.32 & 3.48 & $15.8 \pm 0.8$ & $32 \pm 3$ & $6.49 \pm 0.6$ \\
\hline$p-\mathrm{Br}$ & 6.18 & 5.36 & 4.59 & 3.75 & $15.0 \pm 0.7$ & $29 \pm 2$ & $6.62 \pm 0.5$ \\
\hline$p$-NHAc & 5.85 & 5.05 & 4.24 & 3.42 & $16.0 \pm 0.7$ & $33 \pm 2$ & $6.46 \pm 0.6$ \\
\hline$p-\mathrm{NH}_{2}$ & 5.32 & 4.50 & 3.72 & 2.88 & $17.9 \pm 0.9$ & $40 \pm 3$ & $6.17 \pm 0.7$ \\
\hline$m-\mathrm{Me}$ & 6.02 & 5.22 & 4.41 & 3.59 & $15.5 \pm 0.7$ & $31 \pm 2$ & $6.54 \pm 0.5$ \\
\hline$m$-OMe & 6.13 & 5.31 & 4.53 & 3.71 & $15.1 \pm 0.6$ & $29 \pm 2$ & $6.59 \pm 0.5$ \\
\hline$m-\mathrm{Cl}$ & 5.99 & 5.20 & 4.39 & 3.57 & $15.6 \pm 0.7$ & $31 \pm 2$ & $6.53 \pm 0.6$ \\
\hline$m-\mathrm{Br}$ & 5.45 & 4.68 & 3.81 & 3.05 & $17.3 \pm 0.8$ & $37 \pm 3$ & $6.25 \pm 0.6$ \\
\hline$m-\mathrm{NO}_{2}$ & 5.66 & 4.86 & 4.05 & 3.24 & $16.6 \pm 0.8$ & $35 \pm 2$ & $6.36 \pm 0.6$ \\
\hline$m-\mathrm{CO}_{2} \mathrm{Me}$ & 6.20 & 5.40 & 4.55 & 3.73 & $15.4 \pm 0.7$ & $30 \pm 2$ & $6.62 \pm 0.5$ \\
\hline$o-\mathrm{Me}$ & 5.27 & 4.45 & 3.64 & 2.88 & $17.8 \pm 0.7$ & $40 \pm 2$ & $6.14 \pm 0.6$ \\
\hline$o$-OMe & 5.56 & 4.77 & 3.96 & 3.15 & $16.8 \pm 0.8$ & $36 \pm 3$ & $6.31 \pm 0.6$ \\
\hline$o-\mathrm{NO}_{2}$ & 5.31 & 4.52 & 3.70 & 2.93 & $17.6 \pm 0.9$ & $39 \pm 3$ & $6.17 \pm 0.6$ \\
\hline$o$-COOMe & 6.03 & 5.25 & 4.40 & 3.63 & $15.4 \pm 0.6$ & $30 \pm 3$ & $6.55 \pm 0.5$ \\
\hline$o-\mathrm{Cl}$ & 5.94 & 5.15 & 4.33 & 3.53 & $15.7 \pm 0.7$ & $31 \pm 2$ & $6.51 \pm 0.5$ \\
\hline$o-\mathrm{Br}$ & 5.49 & 4.65 & 3.90 & 3.05 & $17.2 \pm 0.9$ & $37 \pm 3$ & $6.26 \pm 0.7$ \\
\hline$o-\mathrm{I}$ & 6.05 & 5.26 & 4.42 & 3.66 & $15.3 \pm 0.6$ & $30 \pm 2$ & $6.56 \pm 0.5$ \\
\hline$o-\mathrm{NH}_{2}$ & 5.98 & 5.20 & 4.33 & 3.58 & $15.6 \pm 0.6$ & $31 \pm 2$ & $6.52 \pm 0.5$ \\
\hline \multicolumn{8}{|c|}{ (ii) Alkyl phenyl sulfides } \\
\hline $\mathrm{Et}$ & 6.18 & 5.41 & 4.53 & 3.72 & $15.4 \pm 0.7$ & $30 \pm 2$ & $6.62 \pm 0.6$ \\
\hline $\operatorname{Pr}$ & 5.91 & 5.12 & 4.32 & 3.45 & $16.0 \pm 0.8$ & $33 \pm 3$ & $6.49 \pm 0.7$ \\
\hline$i-\operatorname{Pr}$ & 5.45 & 4.68 & 3.86 & 3.06 & $17.1 \pm 0.8$ & $37 \pm 3$ & $6.26 \pm 0.7$ \\
\hline$t$-Bu & 5.86 & 5.04 & 4.23 & 3.45 & $15.9 \pm 0.6$ & $32 \pm 2$ & $6.46 \pm 0.5$ \\
\hline \multicolumn{8}{|c|}{ (iii) Other sulfides } \\
\hline
\end{tabular}

Solvent effect: The rate constants for oxidation, $\mathrm{k}_{2}$, in eighteen solvents $\left(\mathrm{CS}_{2}\right.$ was not considered, as the complete range of solvent parameters was not available) were correlated in terms of the linear solvation energy relationship (eqn. 6) of Kamlet et al. ${ }^{13}$.

$$
\log \mathrm{k}_{2}=\mathrm{A}_{0}+\mathrm{p} \pi^{*}+\mathrm{b} \beta+\mathrm{a} \alpha
$$

In this equation, $\pi^{*}$ represents the solvent polarity, $\beta$ the hydrogen bond acceptor basicities and $\alpha$ is the hydrogen bond donor acidity. $\mathrm{A}_{0}$ is the intercept term. It may be mentioned here that out of the 18 solvents, 13 have a value of zero for $\alpha$. The results of correlation analyses in terms of eqn. 6 , a biparametric equation involving $\pi^{*}$ and $\beta$ and separately with $\pi^{*}$ and $\beta$ are given below in eqn. $7-10$. We have used the standard deviation ( $\mathrm{sd}$ ), the coefficient of multiple determination $\left(\mathrm{R}^{2}\right)$ and Exner's ${ }^{14}$ parameter, $\psi$, as the measures of goodness of fit. Here $n$ is the number of data points.

$$
\begin{aligned}
& \log \mathrm{k}_{2}=-4.25+1.81( \pm 0.20) \pi^{*}+0.13 \\
& ( \pm 0.16) \beta+0.34( \pm 0.16) \alpha \\
& \mathrm{R}^{2}=0.8735 ; \mathrm{sd}=0.18 ; \mathrm{n}=18 ; \psi=0.39 \\
& \log \mathrm{k}_{2}=-4.33+1.69( \pm 0.21) \pi^{*}+0.24( \pm 0.17) \beta(8) \\
& \mathrm{R}^{2}=0.8316 ; \mathrm{sd}=0.20 ; \mathrm{n}=18 ; \psi=0.44 \\
& \log \mathrm{k}_{2}=-4.38+1.75( \pm 0.21) \pi^{*} \\
& \mathrm{r}^{2}=0.8101 ; \mathrm{sd}=0.21 ; \mathrm{n}=18 ; \psi=0.45
\end{aligned}
$$

$$
\begin{aligned}
& \log \mathrm{k}_{2}=-2.69+0.54( \pm 0.38) \beta \\
& \mathrm{r}^{2}=0.1153 ; \mathrm{sd}=0.45 ; \mathrm{n}=18 ; \mathrm{y}=0.97
\end{aligned}
$$

Kamlet's ${ }^{13}$ triparametric equation explains $87 \%$ of the effect of solvent on the oxidation. However, by Exner's criterion the correlation is not even satisfactory (cf. eqn. 7). The major contribution is of solvent polarity. It alone accounted for $81 \%$ of the data. Both $\beta$ and $\alpha$ play relatively minor roles.

The data on the solvent effect were analyzed in terms of Swain's equation ${ }^{15}$ of cation- and anion-solvating concept of the solvents as well.

$$
\log \mathrm{k}_{2}=\mathrm{aA}+\mathrm{bB}+\mathrm{C}
$$

Here A represents the anion-solvating power of the solvent and $\mathrm{B}$ the cation-solvating power. $\mathrm{C}$ is the intercept term. The rates in different solvents were analysed in terms of eqn. 11, separately with $\mathrm{A}$ and $\mathrm{B}$ and with $(\mathrm{A}+\mathrm{B})$.

$$
\begin{aligned}
& \log \mathrm{k}_{2}=1.36( \pm 0.04) \mathrm{A}+1.68( \pm 0.03) \mathrm{B}-3.99 \\
& \mathrm{R}^{2}=0.9956 ; \mathrm{sd}=0.03 ; \mathrm{n}=19 ; \mathrm{y}=0.07 \\
& \log \mathrm{k}_{2}=1.12( \pm 0.55) \mathrm{A}-2.83 \\
& \mathrm{r}^{2}=0.1946 ; \mathrm{sd}=0.45 ; \mathrm{n}=19 ; \mathrm{y}=0.92 \\
& \log \mathrm{k}_{2}=1.58( \pm 0.24) \mathrm{B}-3.56 \\
& \mathrm{r}^{2}=0.7126 ; \mathrm{sd}=0.27 ; \mathrm{n}=19 ; \mathrm{y}=0.55 \\
& \log \mathrm{k}_{2}=1.57 \pm 0.05(\mathrm{~A}+\mathrm{B})-3.94 \\
& \mathrm{r}^{2}=0.9846 ; \mathrm{sd}=0.02 ; \mathrm{n}=19 ; \mathrm{y}=0.13
\end{aligned}
$$


TABLE - 5

SOLVENT EFFECT ON THE OXIDATION OF MESPH BY IFC AT $318 \mathrm{~K}$

\begin{tabular}{lcclcc}
\hline Solvents & $\mathrm{K}\left(\mathrm{dm}^{-3} \mathrm{~mol}^{-1}\right)$ & $10^{4} k_{2}\left(\mathrm{~s}^{-1}\right)$ & Solvents & $\mathrm{K}\left(\mathrm{dm}^{-3} \mathrm{~mol}^{-1}\right)$ & 5.31 \\
\hline Chloroform & 5.67 & 70.8 & Toluene & 6.21 & $10^{4} k_{2}\left(\mathrm{~s}^{-1}\right)$ \\
1,2-Dichloroethane & 4.86 & 66.1 & Acetophenone & 4.75 & 67.6 \\
Dichloromethane & 4.54 & 57.5 & THF & 4.38 & 25.7 \\
DMSO & 4.59 & 209 & $t$-butylalcohol & 4.27 & 27.5 \\
Acetone & 5.76 & 47.9 & 1,4 -Dioxane & 5.40 & 26.3 \\
DMF & 4.70 & 98.1 & 1,2 -Dimethoxyethane & 4.95 & 12.6 \\
Butanone & 5.94 & 39.8 & CS & 5.90 & 5.62 \\
Nitrobenzene & 4.32 & 63.1 & Acetic acid & 5.40 & 32.4 \\
Benzene & 6.20 & 17.4 & Ethyl acetate & & 18.2 \\
Cyclohexane & 5.62 & 1.45 & & & \\
\hline
\end{tabular}

The rates of oxidation of methyl phenyl sulfide in the different solvents show an excellent correlation with Swain's equation with both the cation- and anion-solvating powers playing significant roles, though the contribution of the cationsolvation is slightly more than that of the anion-solvation. However, the correlations individually with A and B were poor. In view of the fact that solvent polarity is able to account for 99 $\%$ of the data, an attempt was made to correlate the rate with the relative permittivity of the solvent.

However, a plot of $\log \mathrm{k}_{2}$ against the inverse of the relative permittivity is not linear $\left(r^{2}=0.4766 ; s d=0.36 ; \psi=0.74\right)$.

Correlation analysis of reactivity: The oxidation of different sulfides follows the order of their nucleophilicity: $\operatorname{Pr}_{2} \mathrm{~S}>$ $\mathrm{Me}_{2} \mathrm{~S}>\mathrm{MeSPh}>\mathrm{Ph}_{2} \mathrm{~S}$.

(i) Aryl methyl sulfides: The correlation of the effect of substituents on the reactivity has been widely attempted in terms of the Hammett eqn. ${ }^{16}$ or with dual substituent-parameter eqn. ${ }^{17,18}$. Charton ${ }^{19}$ introduced a triparametric LDR equation for the quantitative description of structural effects on chemical reactivities. This triparametric equation results from the fact that substituent types differ in their mode of electron delocalization. This difference is reflected in a different sensitivity to the electronic demand for the phenomenon being studied. It has the advantage of not requiring a choice of parameters as the same three substituent constants are reported to cover the entire range of electrical effects of substituents. We have, therefore, begun a study of structural effects on reactivity by means of the LDR equation. In this work, we have applied the LDR eqn. 16 to the rate constants, $\mathrm{k}_{2}$.

$$
\log \mathrm{k}_{2}=\mathrm{L} \sigma_{1}+\mathrm{D} \sigma_{\mathrm{d}}+\mathrm{R} \sigma_{\mathrm{e}}+\mathrm{h}
$$

Here, $\sigma_{1}$ is a localized (field and/or inductive) effect parameter, $\sigma_{\mathrm{d}}$ is the intrinsic delocalized (resonance) electrical effect parameter when active site electronic demand is minimal and $\sigma_{\mathrm{e}}$ represents the sensitivity of the substituent to changes in electronic demand by the active site. The latter two substituent parameters are related by eqn. 17.

$$
\sigma_{\mathrm{D}}=\eta \sigma_{\mathrm{e}}+\sigma_{\mathrm{d}}
$$

Here $\eta$ represents the electronic demand of the reaction site and represents the ratio of regression coefficient of the sensitivity parameter, $\sigma_{\mathrm{e}}$ and that of resonance parameter, $\sigma_{\mathrm{d}}$ i.e. $\eta$ $=\mathrm{R} / \mathrm{D} . \sigma_{\mathrm{D}}$ represents the delocalized electrical parameter of the diparametric LD equation.

For ortho-substituted compounds, it is necessary to account for the possibility of steric effects and Charton ${ }^{19}$ therefore, modified the LDR equation to generate the LDRS eq. 18 .

$$
\log \mathrm{k}_{2}=\mathrm{L} \sigma_{1}+\mathrm{D} \sigma_{\mathrm{d}}+\mathrm{R} \sigma_{\mathrm{e}}+\mathrm{S} v+\mathrm{h}
$$

where $v$ is the well-known Charton's steric parameter based on van der Waals radii ${ }^{20}$.

The rates of oxidation of ortho-, meta- and para- substituted sulfides show excellent correlations in terms of the LDR/ LDRS equations (Table-4). The values of the independent variables, $\sigma_{1}, \sigma_{\mathrm{d}}, \sigma_{\mathrm{e}}$ and $v$, were obtained from the work of Charton and Charton ${ }^{19}$. Though the number of data-points is less than the optimum number, the correlations are excellent as per Exner's ${ }^{14}$ criterion also. Exner's $\psi$ parameter takes into account the number of data-point also.

All three regression coefficients, L, D and R, are negative indicating an electron-deficient sulfur center in the transition state of the rate-determining step. The positive value of $\eta$ adds a negative increment to $\sigma_{\mathrm{d}}$ as in eqn. 18 , reflecting the electrondonating power of the substituent and its capacity to stablize a cationic species.

The negative value of $\mathrm{S}$ indicates that the reaction is subjected to steric hindrance by the ortho-substituent. This may be due to steric hindrance of the ortho-substituent to the approach of the oxidizing species.

To test the significance of localized, delocalized and steric effects in the ortho-substituted sulfides, multiple linear regression analyses were carried out with (i) $\sigma_{\mathrm{l}}, \sigma_{\mathrm{d}}$ and $\sigma_{\mathrm{e}}$, (ii) $\sigma_{\mathrm{d}}, \sigma_{\mathrm{e}}$ and $v$ and (iii) $\sigma_{1}, \sigma_{\mathrm{e}}$ and $v$. The absence of significant correlations [eqn. 19-21] showed that all the four substituent constants are significant.

$$
\begin{aligned}
& \log \mathrm{k}_{2}=-2.01( \pm 0.47) \sigma_{1}-1.33( \pm 0.39) \\
& \sigma_{d}-1.98( \pm 2.74) \sigma_{e}-3.17 \\
& \mathrm{R}^{2}=0.8941, \mathrm{sd}=0.29, \mathrm{n}=10, \psi=0.40 \\
& \log \mathrm{k}_{2}=-1.89( \pm 0.44) \sigma_{\mathrm{d}}+0.54( \pm 0.18) \\
& \sigma_{\mathrm{e}}-1.84( \pm 0.55) v-2.94 \\
& \mathrm{R}^{2}=0.8506, \mathrm{sd}=0.34, \mathrm{n}=10, \psi=0.47 \\
& \log \mathrm{k}_{2}=-2.13( \pm 0.88) \sigma_{1}-5.37( \pm 4.39) \\
& \sigma_{\mathrm{e}}-0.70( \pm 0.88) v-2.72 \\
& \mathrm{R}^{2}=0.6837, \mathrm{sd}=0.50, \mathrm{n}=10, \psi=0.69
\end{aligned}
$$

Similarly in the cases of the oxidation of para- and metasubstituted sulfides, multiple regression analyses indicated that both localization and delocalization effects are significant. There is no significant collinearity between the various substituent constants for the three series. 
TABLE - 6

CORRELATION OF RATE OF OXIDATION OF ALKYL PHENYL SULFIDES WITH PAVELICH-TAFT EQUATION ${ }^{\mathrm{A}}$

\begin{tabular}{ccccc}
\hline Temperature $\mathrm{K}$ & $\rho^{*}$ & $\delta$ & $\mathrm{R}^{2}$ & $\mathrm{sd}$ \\
\hline 288 & $-2.79 \pm 0.02$ & $0.80 \pm 0.01$ & 0.9999 & 0.01 \\
298 & $-2.81 \pm 0.10$ & $0.78 \pm 0.02$ & 0.9993 & 0.03 \\
308 & $-2.87 \pm 0.23$ & $0.76 \pm 0.04$ & 0.9957 & 0.08 \\
318 & $-2.85 \pm 0.25$ & $0.69 \pm 0.05$ & 0.9832 & 0.11 \\
\hline
\end{tabular}

TABLE - 7

TEMPERATURE DEPENDENCE FOR THE REACTION CONSTANTS FOR THE OXIDATION OF ORGANIC SULFIDES BY IFC

\begin{tabular}{|c|c|c|c|c|c|c|c|c|c|c|}
\hline $\mathrm{T} / \mathrm{K}$ & $-\mathrm{L}$ & $-\mathrm{D}$ & $-\mathrm{R}$ & $-S$ & $\eta$ & $\mathrm{R}^{2}$ & sd & $\psi$ & $\mathrm{P}_{\mathrm{D}}$ & $P_{S}$ \\
\hline \multicolumn{11}{|c|}{ para-substituted } \\
\hline 288 & 1.44 & 1.80 & 1.53 & - & 0.85 & 0.9999 & 0.001 & 0.01 & 37.7 & - \\
\hline 298 & 1.35 & 1.70 & 1.44 & - & 0.85 & 0.9998 & 0.002 & 0.02 & 37.9 & - \\
\hline 308 & 1.26 & 1.62 & 1.34 & - & 0.83 & 0.9989 & 0.001 & 0.04 & 38.4 & - \\
\hline 318 & 1.17 & 1.52 & 1.28 & - & 0.84 & 0.9999 & 0.003 & 0.01 & 38.3 & - \\
\hline \multicolumn{11}{|c|}{ meta-substituted } \\
\hline 288 & 1.80 & 1.44 & 1.19 & - & 0.83 & 0.9999 & 0.001 & 0.01 & 32.5 & - \\
\hline 298 & 1.71 & 1.36 & 1.09 & - & 0.80 & 0.9998 & 0.002 & 0.02 & 32.7 & - \\
\hline 308 & 1.62 & 1.26 & 0.97 & - & 0.77 & 0.9999 & 0.001 & 0.01 & 32.7 & - \\
\hline 318 & 1.51 & 1.18 & 0.82 & - & 0.69 & 0.9998 & 0.005 & 0.02 & 33.6 & - \\
\hline \multicolumn{11}{|c|}{ ortho-substituted } \\
\hline 288 & 1.54 & 1.62 & 1.34 & 1.26 & 0.83 & 0.9999 & 0.005 & 0.01 & 36.0 & 21.9 \\
\hline 298 & 1.48 & 1.53 & 1.25 & 1.17 & 0.82 & 0.9989 & 0.002 & 0.04 & 36.3 & 21.7 \\
\hline 308 & 1.35 & 1.44 & 1.15 & 1.08 & 0.80 & 0.9999 & 0.001 & 0.01 & 36.5 & 21.5 \\
\hline 318 & 1.27 & 1.34 & 1.14 & 0.99 & 0.85 & 0.9998 & 0.005 & 0.02 & 35.7 & 21.0 \\
\hline
\end{tabular}

The percent contribution ${ }^{20}$ of the delocalized effect, $\mathrm{P}_{\mathrm{D}}$ is given by the following eqn. 22 .

$$
\mathrm{P}_{\mathrm{D}}=(|\mathrm{D}| \times 100) /(|\mathrm{L}|+|\mathrm{D}|+|\mathrm{R}|)
$$

Similarly, the per cent contribution of the steric parameter ${ }^{20}$ to the total effect of the substituent, $\mathrm{P}_{\mathrm{S}}$, was determined by using eqn. 23 .

$$
\mathrm{P}_{\mathrm{S}}=(|\mathrm{S}| \times 100) /(|\mathrm{L}|+|\mathrm{D}|+|\mathrm{S}|+|\mathrm{R}|)
$$

The values of $P_{D}$ and $P_{S}$ are also recorded in Table-7. The value of $\mathrm{P}_{\mathrm{D}}$ for the oxidation of para-substituted sulfides is $52 \%$ whereas the corresponding values for the meta- and ortho-sobstituted aldehydes are 39 and $49 \%$ respectively. The less pronounced resonance effect from the ortho- position than from the para-position may be due to the twisting away of the methyl-thio group from the plane of the benzene ring.

In earlier studies on the oxidations of sulfides, involving a direct oxygen transfer via an electrophilic attack on the sulfidesulfur, the reaction constants were negative but of relatively small magnitude, $e . g$. by hydrogen peroxide $(-1.13)^{21}$, periodate $(-1.40)^{22}$, permanganate $(-1.52)^{23}$ and peroxydisulfate $(-0.56)^{24}$. Large negative reaction constants were exhibited by oxidations involving formation of halogeno-sulfonium cations e.g. by chloramine-T $(-4.25)^{25}$, bromine $(-3.2)^{26}$ and N-bromoacetamide $(-3.75)^{27}$.

In the oxidation by $\mathrm{N}$-chloroacetamide $(\mathrm{NCA})^{28}$ the values of field $\left(\rho_{\mathrm{I}}\right)$ and resonance $\left(\rho_{\mathrm{R}}^{+}\right)$, at $298 \mathrm{~K}$ are -1.3 and -1.7 , respectively.

(ii) Alkyl phenyl sulfides: The rates of oxidation of alkyl phenyl sulfides did not yield any significant correlation separately with Taft's $\sigma^{*}$ or $\mathrm{E}_{\mathrm{s}}$ values. The rates were therefore analysed in terms of Pavelich-Taft's ${ }^{29}$ dual substituent-parameter (DSP) eqn. 24.

$$
\log \mathrm{k}_{2}=\rho^{*} \sigma^{*}+\delta \mathrm{E}_{\mathrm{s}}+\log \mathrm{k}_{0}
$$

The correlations are excellent (Table-6). Though the number of compounds is small (five) for any analysis by a DSP equation, the results can be used qualitatively. The negative polar reaction constant confirms that the electron-donating power of the alkyl group enhances the reaction rate. The steric effect plays a minor inhibitory role.

\section{Mechanism}

The observed dependence on $\mathrm{TsOH}$ suggests that the reaction follows two mechanistic pathways, one $\mathrm{TsOH}-$ catalyzed and the other uncatalyzed. The catalytic effect of TsOH can be attributed to a protonation of TEACC to give a stronger oxidant and electrophile (25).

\section{$\mathrm{O}_{2} \mathrm{CrClOImH}+\mathrm{TsOH} \rightleftharpoons[\mathrm{OCr}(\mathrm{OH}) \mathrm{ClOImH}]^{+}[\mathrm{TsO}]^{-}(25)$}

In view of the absence of any effect of radical scavenger, acrylonitrile, on the reaction rate, it is unlikely that a one electron reaction giving rise to free radicals, is operative in this oxidation. The observed Michaelis-Menten kinetics with respect to sulfides led us to suggest the formation of a 1:1 complex of IFC and sulfides in a rapid pre-equilibrium. With present set of data, it is difficult to state the definite nature of the intermediate complex. Theoretical calculations [30] have shown that there is a substantial charge transfer from the metal to the oxygen in dichromate. The most logical mode of interaction between sulfides and IFC would, therefore be nucleophilic attack at the metal. Donation of a unshared pair of electrons to an empty $d$-orbital on the metal would result in the formation of a coordinate covalent bond. The initial formed intermediate is likely to undergo a further rapid reaction in which the incipient oxide and sulfonium ions bond to form a highly structured 
intermediate, that would rearrange to give a sulfoxide (Scheme-I)

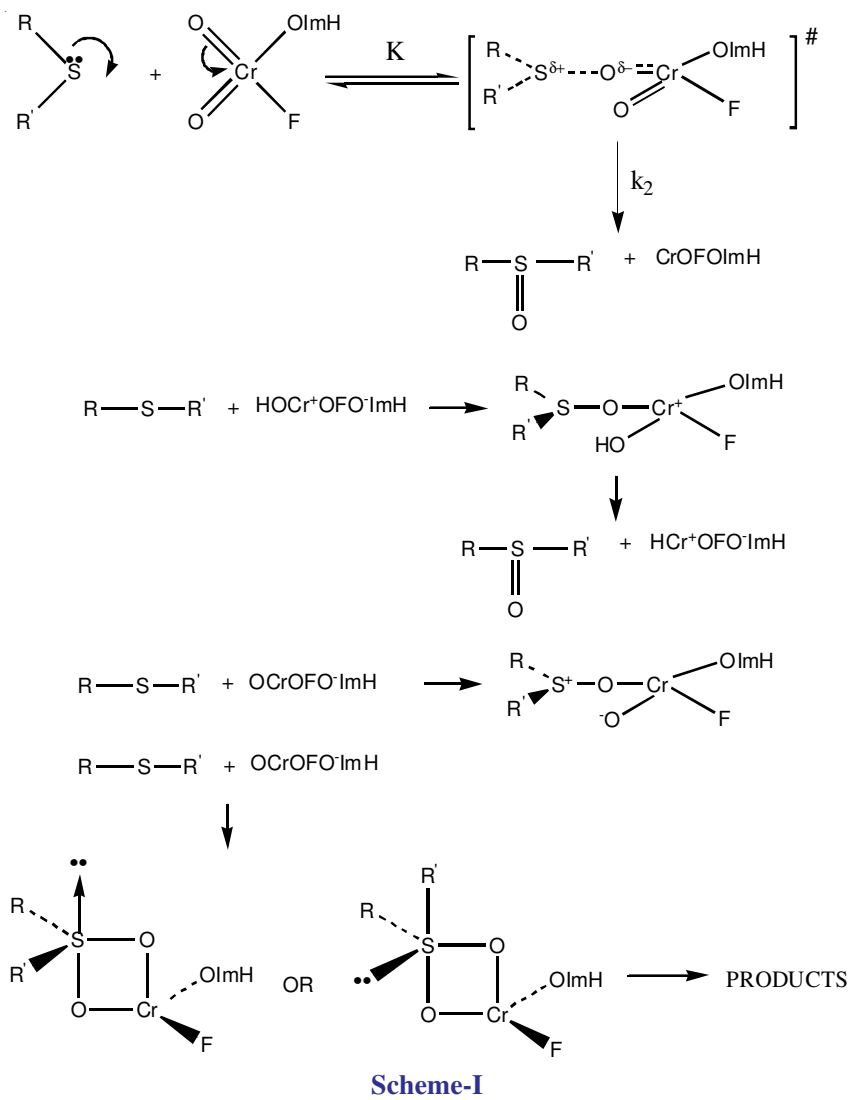

The oxidation of sulfides by IFC may involve a cyclic intermediate as has been suggested in many reactions of $\mathrm{Cr}(\mathrm{VI})$. The cyclic transition state will be highly strained in view of the apical position of a lone pair of electrons or an alkyl group (25). The steric requirements of the reaction (25) will be higher as compared to those of reaction (Scheme-I) and the observed small magnitudes of steric reaction constants are thus consistent with the proposed acyclic mechanism. The formation of a cyclic transition state entails a more exacting specificity of orientation and should result in much larger negative entropy of activation than that observed.

\section{ACKNOWLEDGEMENTS}

Thanks are due to University Grants Commission, New Delhi for financial support in the form of BSR-One Time Grant, No. F. 4-10/2010 (BSR) dated 07.03.2012.

\section{REFERENCES}

1. E.J. Corey and W.J. Suggs, Tetrahedron Lett., 16, 2647 (1975).

2. A. Pandurangan, A. Rajkumar, G.A. Arabindoo and V. Murugesan, Indian J. Chem., 38B, 99 (1999).

3. N. Malani, M. Baghmar and P.K. Sharma, Int. J. Chem. Kinet., 41, 65 (2009).

4. P. Swami, N. Malani, S. Agarwal and P.K. Sharma, Prog. React. Kinet. Mech., 35, 309 (2010).

5. D. Sharma, P. Pancharia, K. Vadera and P.K. Sharma, J. Sulfur Chem., 32, 315 (2011).

6. D. Sharma, P. Panchariya, P. Purohit and P.K. Sharma, Oxid. Commun., 35, 821 (2012).

7. C. Karunakaran, R. Venkataramanan and R. Kamalam, Monatsh. Chem., 130, 1461 (1999)

8. T. Zincke and J. Müller, Chem Ber., 46, 775 (1913) ; T. Zincke and G. Siebert, Chem Ber., 48, 1242 (1915); A.W. Hofmann, Chem Ber., 20, 2251 (1887); H. Gilman and G.C. Gainer, J. Am. Chem. Soc., 71, 1747 (1949); A.J. Saggiomo, P.N. Craig and M. Gordon, J. Org. Chem., 23, 1906 (1958); E.A. Nodiff, S.Y. Lipschutz, P.N. Craig and M. Gordon, J. Org. Chem., 25, 60 (1960).

9. C.J. Pouchart, The Aldrich Library of IR Spectra, edn 3 (1981).

10. C.J. Pouchart, The Aldrich Library of NMR Spectra, edn. 1st and 2nd (1983).

11. L. Liu and Q.-X. Guo, Chem. Rev., 101, 673 (2001).

12. O. Exner, Collect. Chem. Czech. Commun., 29, 1094 (1964).

13. M.J. Kamlet, J.L.M. Abboud, M.H. Abraham and R.W. Taft, J. Org. Chem., 48, 2877 (1983)

14. O. Exner, Collect. Chem. Czech. Commun., 31, 3222 (1966).

15. C.G. Swain, M.S. Swain, A.L. Powel and S. Alunni, J. Am. Chem. Soc., 105, 502 (1983).

16. C.D. Johnson, The Hammett Equation, University Press, Cambridge, p. 78 (1973).

17. S. Ehrenson, R.T.C. Brownlee and R.W. Taft, J. Am. Chem. Soc., 96, 9113 (1974).

18. C.G. Swain, S.H. Unger, N.R. Rosenquist and M.S. Swain, J. Am. Chem. Soc., 105, 492 (1983).

19. M. Charton and B. Charton, Bull. Soc Chim Fr., 199 (1988) and references cited therein.

20. M. Charton, J. Org. Chem., 40, 407 (1975).

21. G. Modena and L. Maioli, Gazz. Chim. Ital., 87, 1306 (1957).

22. F. Ruff and A. Kucsman, J. Chem. Soc., Perkin Trans. II, 683 (1985).

23. K.K. Banerji, Tetrahedron, 44, 2969 (1988).

24. C. Srinivasan, P. Kuthalingam and N. Arumugam, Can. J. Chem., 56, 3043 (1978).

25. F. Ruff and A. Kucsman, J. Chem. Soc., Perkin Trans. II, 509 (1975).

26. U. Miotti, G. Modena and L. Sadea, J. Chem. Soc. B, 802 (1970).

27. S. Perumal, S. Alagumalai, S. Selvaraj and N. Arumugam, Tetrahedron, 42, 4867 (1986).

28. A. Agarwal, P. Bhatt and K.K. Banerji, J. Phys. Org. Chem., 3, 174 (1990).

29. W.H. Pavelich and R.W. Taft, J. Am. Chem. Soc., 79, 4935 (1957). 